
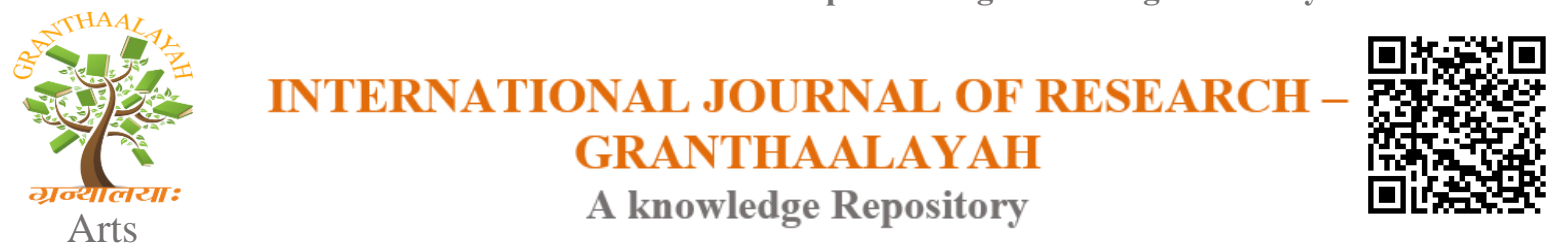

\title{
NEW HORIZON FOR AIPAN (FOLK ART OF UTTARAKHAND) MOTIFS THROUGH APPLIQUÉ
}

\author{
Monika Negi*1, Anita Rani ${ }^{2}$, Anupriya Singh ${ }^{3}$ \\ ${ }^{* 1}$ Ph.D Student, Dept of Clothing \& Textiles, College of Home Science, G.B.P.U.A.T, \\ Uttarakhand, INDIA \\ ${ }^{2}$ Assistant Professor, Dept of Clothing \& Textiles, College of Home Science, G.B.P.U.A.T, \\ Uttarakhand, INDIA \\ ${ }^{3}$ Ph.D. Student, Dept of Clothing \& Textiles, College of Home Science, G.B.P.U.A.T, \\ Uttarakhand, INDIA
}

\begin{abstract}
The Indian folk arts with printing and embroidery play important role in creating new designs. Escalating demands of consumers requires modification in the fashion industry with respect to design, colour, style and technique. So an attempt was made to develop a design pool using folk art of Uttarakhand (aipan) for applique work. This also provides the opportunity to use the adapted traditional motifs on textiles and to preserve the beautiful traditional folk art. Aipan motifs were adapted for center design, border design, and buti design. Total thirty motifs / designs were developed keeping in mind their suitability for articles like bags, pencil purse and mobile holder. All the developed designs were subjected to visual evaluation for selection of two best designs in each category by the panel of thirty judges to find out the suitability of the developed designs for appliqué work. Thus total six motifs were selected for preparation of the five arrangements for each article. Four final selected arrangements with appliqué work were prepared using different embroidery stitches (slip hemming, couching, buttonhole and chain stitch). Plain red poplin and left-out fabrics were used to prepare articles. Finally articles were prepared by using selected arrangements and these prepared articles were highly appreciated by the consumers.
\end{abstract}

Keywords:

Textile designing, Eco fashion, adaptation, Applique, aipan, fusion.

Cite This Article: Monika Negi, Anita Rani, and Anupriya Singh, "NEW HORIZON FOR AIPAN (FOLK ART OF UTTARAKHAND) MOTIFS THROUGH APPLIQUÉ” International Journal of Research - Granthaalayah, Vol. 3, No. 9(2015): 36-48.

\section{INTRODUCTION}

Colour has always fascinated man and has played a dominant role in adding beauty to the world. It expresses emotions and ideas. Sensitivity to colour has been revealed in paintings, poetry, music and costumes [1]. The applying of colour to textile material can be done through many ways like 
dyeing, printing, painting, and even embroidery or appliqué are also used to add aesthetic appeal to fabric or textile surface. The sheer abundance of colour in form of art and craft in India, have attracted most of the people worldwide.

Textile designing is full of creativity and scope with vast horizon, and is a demanding and emerging field. Throughout time, textile designers from all over the world have been inspired to decorate their fabrics by looking at many things either natural or manmade. In the same manner, the rich motifs and designs of the various arts and crafts can be readily adapted into contemporary forms [2].

Many researchers are engaged in using the folk as sources of inspiration and also adapting traditional motifs to make them suitable to incorporate them into textile products like adaptation of warli, madubani and kalamkari for different apparels like kurta, suit, sarees and dupataas.

India's indigenous arts and crafts remain veiled in mystery. It is easy to recognise art categorised as "folk" and "tribal" - stylised figures, flat renderings, repetitive motifs, and themes immersed in ritual, religion and festivity dominate [3]. Folk painting or folk art is a comprehensive term for work of art not executed by individual artist but originated with an anonymous ethnic group.

Folk art in India apparently has a great potential in the international market because of its traditional aesthetic sensibility and authenticity. The rural folk paintings of India bear distinctive colorful designs, which are treated with religious and mystical motifs. Some of the the most famous folk art or paintings of India are Patachitra \& Saura paintings of Orissa, kalamkari \& Nirmal paintings of Andhra Pradesh, Gond art \& Mandana Paintings of Madhya Pradesh and Rajasthan, Warli Painting of Maharashtra, Kalighat pats of West Bengal and Madhubani paintings of Bihar etc. There are many kinds of ritualistic folk art like Patachitra, Pichuai, Alpana, Kolam etc. One such art form called "aipan" that rest in lush green trees, silvery snow mountains, clear blue sky and vibrating music of bells of Kumaun region in Uttarakhand state [4].

The rich craft heritage of India is unique and diverse as its customs and traditions. Indian craft tradition has no parallel in the world, in diversity as well as in technique and use of materials. The craft traditions of India vary from region to region. These crafts not only cater to the day-to-day needs of the people but are also used for decorative and religious purposes [5].

Uttarakhand is a new state and there is dire need to popularize its art and beauty, and to expose the in-house talent and skills of the people of Kumaun to the outside world. Aipan design, an ancient art is known for its beautiful and intricate design that shows a complex yet balanced combination of geometric abstract and stylized designs [6]. The adaptation of traditional art, for the creation of innovative motif and designs could inhabit a unique place in textile field. The growing demand for such good has created opportunities in the fashion and textile industry with respect to design, colour and technique due to the changes in fashion trends. Aipan designs are good source of folk motifs to be used on textile products. Recently, these designs are being used on many textile items through different surface enrichment technique such as screen printing, block printing, batik embroidery. So, one of the ways to transfer these folk motifs on to the fabric is through appliqué work. Appliqué is a fascinating needle work art form referred to the superimposition of one piece of material upon another usually by the means of stitches. 
Our purpose is to preserve, diversify and to document the the art of Uttarakhand (aipan) through the fusion of the motives with some techniques (the art of appliqué work), to create an embodiment of distinctive and unique design pool.

\section{A GLANCE INTO THE AIPAN (FOLK ART) OF UTTARAKHAND}

India had always been known as the land that portrayed cultural and traditional vibrancy through its conventional arts and crafts. Every region in India has its own style and pattern of art, which is known as folk art. The folk arts of India are very ethnic and simple, and yet colorful and vibrant enough to speak volumes about the country's rich heritage [4].

Uttarakhand, cradled in the lap of the lofty Himalayas, the state boasts of snow-crapled peaks, stealthy glaciers, meandering rivers, mist laden valleys and exotic species of flora and fauna. Inspired by this flawless natural splendor, the people of Uttarakhand have created and nurtured variour forms of arts and crafts since ages. Crafts usually utility items like doors, windows, rugs, carpets, baskets, copper utensils or the folk art Aipan made by Uttarakhandis have a unique touch of nature in their designs [7]

Aipan, a traditional art form with which the Kumaonis particularly women decorate their houses to welcome an auspicious occasion like Diwali or any other event like marriage ceremony, now moves beyond the threshold of the Kumaon [8].The word "Aipan" is actually a derivative of the word "Arpan", a Sanskrit word. The actual meaning of Aipan is "Likhai" that means writing, though it is a pattern that is made with the help of fingers [8]. The women of Kumaun celebrate all festivals and rituals ceremonies by first decorating the floors and entrances of their homes with folk painting called as Aipans [9].

Aipan are designs that are used in Festivals, Pujas and in various Ceremonies related to birth, marriage, and thread ceremony (also called the Janeu) and in case of death as well. Various geometric and other figures belonging to gods, goddesses and other objects of nature are meticulously used for the decoration of the walls, pieces and papers. Aipan is an art that possess a special place in all the Kumaoni homes [10]. An Aipan is made with 'Geru' or red vermillion paste as a base and rice paste patterns on top [11]. This pristine white on deep red gives out a beautiful contrast emphasizing the designs. The rice paste is made by soaking any rice for about 16 hours and then grinding it into a fine paste with a medium to runny consistency. The ring finger of the right hand is used to draw the elaborate patterns with help of cotton balls or cloth [12]. Aipan motifs are drawn on the floor of the room where rituals are performed, in the courtyard, on the steps of the main door, on the threshold, around the mortar, on wooden seats, on pots containing tulsi plants, and at the temple [13].

Women pass on the patterns to their daughters and daughters-in-law [14]. Some of the patterns are significant from a religious point of view and are especially made at the time of ceremonies like marriages, threading ceremony, naming ceremony, etc, to perform rituals. Each and every Aipan design has a particular meaning attached to it and is drawn with a specific purpose in mind [15]. Presently three forms of art are seen in Kumaun region (viz. siddha, Daiva and Laukika) known as Aipan, Patta and bar boond. Folk paintings drawn on ground and walls are the examples of siddha form, the astrological motifs, almanac designs and dwar-patia are the example of Daiva form and 
aesthetic creations of artists, the laukika form of art [13]. Previously the paint that was used was made of natural dyes. But today, to make the product more effective, both poster and oil paints are used. This is an effective form of art this is extensively used in the state of the Uttarakhand [11].

\section{CLASSIFICATION OF AIPAN}

According to Chattopadhay (1981) there are three styles of aipan namely Siddhu, Davia and Loukika.

- Siddhu: It is the style of aipan which drawn on floor and chaukies.

- Davia: It is the form of patta. It has astrological motifs, manual designs and dwar pattas.

- Loukika:it is the style of bar boond. These are drawn on walls.

Later on Sah (2006), classify the aipan in various style. The medium selected for drawing aipan may be different depending upon the purpose or the occasion and variety of patterns and their combination may be used at different occasions.

Classification on the basis of places where aipan are drawn: The drawing of Aipan may be used at different places as given below:

- Floor Painting- Floor painting are drawn on floor. These are further divided into two categories; Aipan drawn at door steps (creepers and filler design) and aipan drawn at place of worships (Shiv peeth, Laxmi peeth, Asan) [17].

- Wall painting- Wall paintings are drawn on the wall. There are two traditional forms of wall painting; one for the kitchen (Nata and Laxmi Narayana) and other for the place where ritual ceremonies are performed (Patas) [12].

- On cloth- Some Aipan designs are also drawn on cloth. For example khodia chauki in pichhora and shiv peeth in yellow colour cloth used in rituals [17].

- Wooden chaukies- These are worships seats of the deities prepared through aipan and used on different occasion like worship, ceremonial occasion or on festivals [17]. 

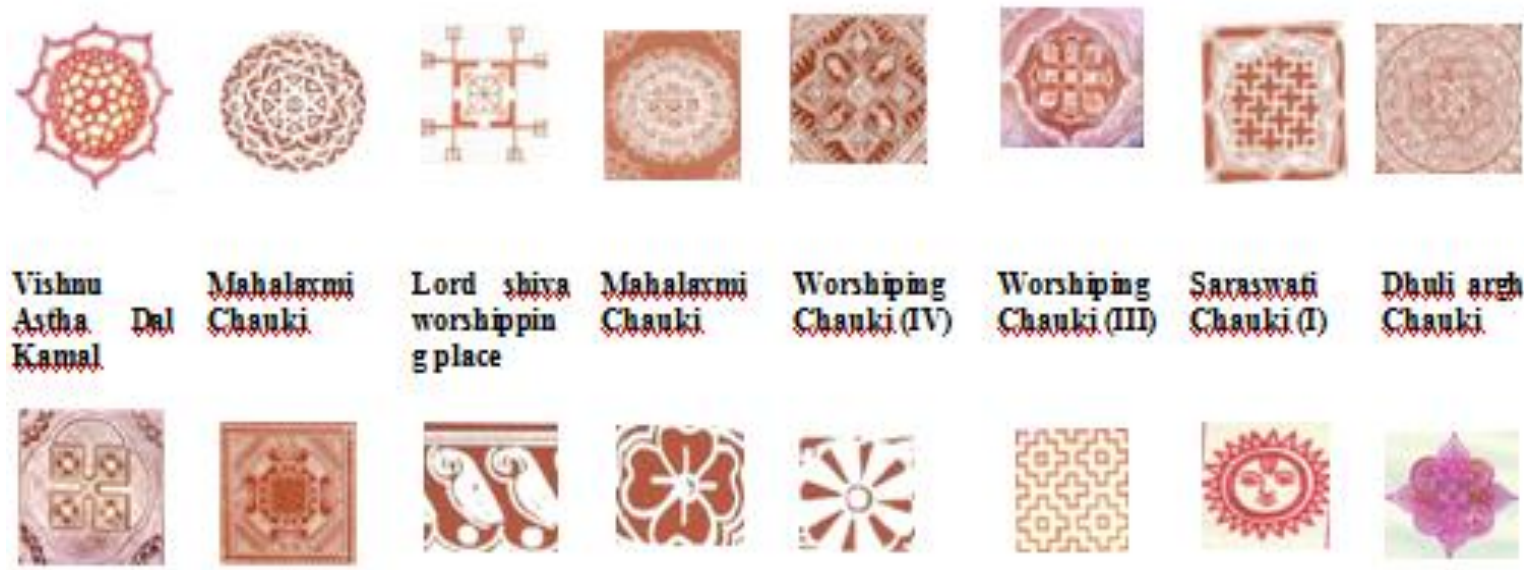

Mahalaxmi

Lord shivg Chapki g place
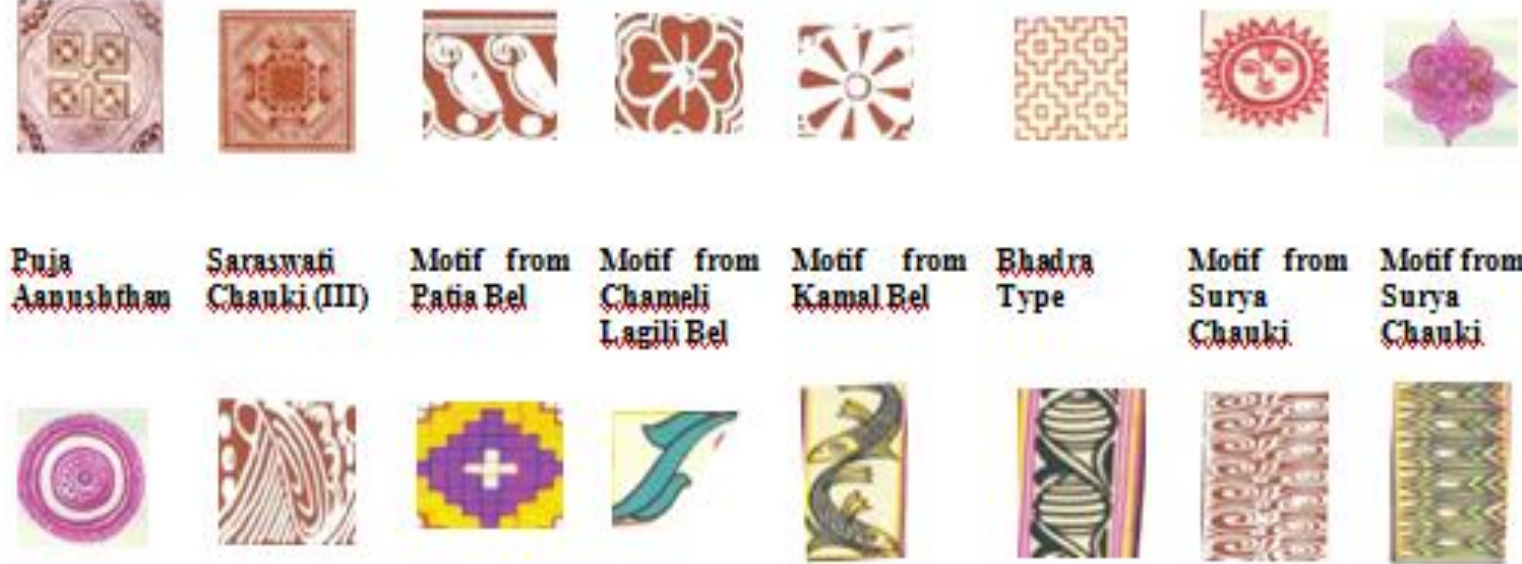

\section{Bhadxs \\ Type}
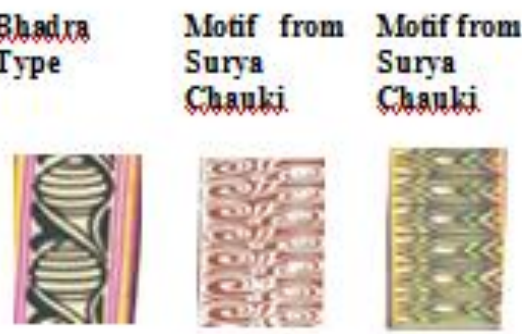

Motif from Motif from Motif from Motif from Surya
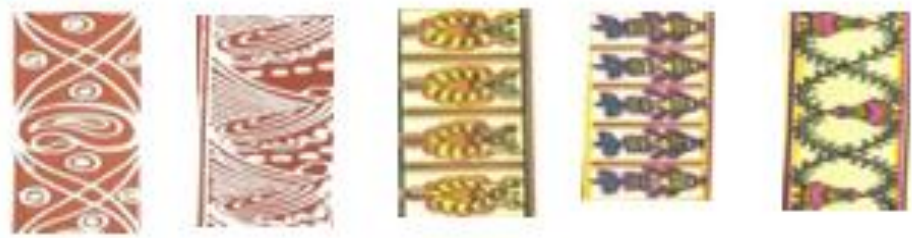

(I)

(I)

Bel Chapaj Bel

Machbis bel

hapkhi Bel

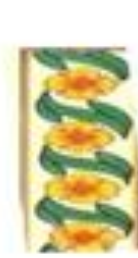

Patis Bel

Bel

\section{Kunji Bel}

(II)

(I)

(II)

\section{Ghanti \\ Ghaneli.Bel}

Figure 1: Selected Original Motifs Of Aipan

\section{Classification on the basis of different forms and shapes of aipan [18,19]}

- Nav Durga Chauki- Nav Durga Ckauki is used for ritual Devi pujas. A simpler version is made by drawing three horizontal and vertical lines with a Swastik in the centre. The main points in this Chauki are nine dots representing the Nav Durgas. 


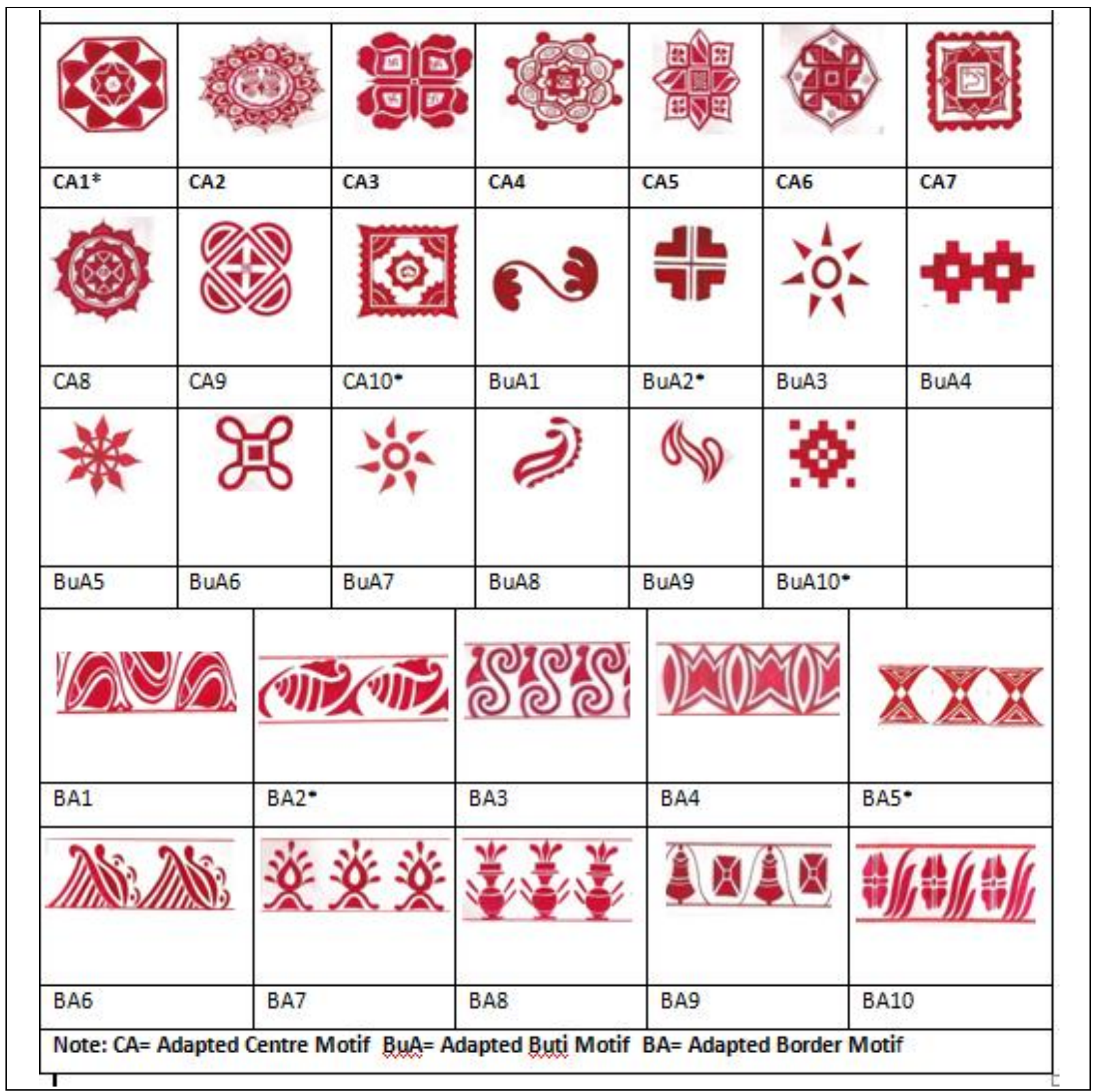

Figure 2: Adaptation Of Original Motifs

- Asan Chauki- This is associated with the many kinds of chaukies used for various pujas. It is a decorated seat for the devotee and his wife for a ritual puja. It is a decorated seat for devotee and his wife for a ritual puja.

- Chamunda Hast Chauki- This Chauki is made for "havans" or "yoga". Two triangles interspersed with two diagonal lines running across both, with a 5-pointed star in between, enclosed in a circle make the centre piece of this Chauki. The gaps are filled up with floral designs or lakshmi's feet. The circle itself is often decorated with 8 petals of the lotus.

- Saraswati Chauki- Saraswati being the Goddess of learning, when a child begins formal education a puja is held to give him/her an auspicious start. The main feature of this Chauki is five- pointed star with a swastika flower or a diya in the centre. 
- Janeu Chauki. This Chauki is made especially for the sacred thread ceremony. Seven stars within a six-sided drawing form the main section. The seven stars represent the Sapt Rishis. Around this floral designs with dots are drawn.

- Shiv or Shivarchan Peeth- Shiv is worshiped especially in the month of savan or magh. Shiv is the reigning God of the people of the Himalayas. He is worshipped especially in the months of Savan or Magh. This is an eight cornered design with 12 dots joined by 12 lines.

\section{Classification on the basis of use of Aipan at different occasion $[17,18,19]$}

a) Birth-Special types of chaukies are prepared for performing ceremonies related to child birth.

- The Surya Darshan Chauki- It is connected with the naming ceremony of a newborn child. For eleven days the baby is kept indoors, on the eleventh day the child is brought outside for Surya Darshan. This Chauki is made on the floor where the priest sits reciting mantras.

- Syo Aipan-Syo Aipan is a geometric pattern drawn toward evil spirit on eleventh day of child birth.

b) Marriage- Three types of chaukies are used to perform ceremonies of marriage.

- Acharya Chauki- The groom is always accompanied among others by his own Pandit or Acharya. The Pandit is given more prominence than even the father of the groom. So a special Chauki is made for him. A Swastik is made on it with red colour. The lotus and other auspicious symbols such as a bell, a conch shell, and sometimes even 2 parrots are painted around the Swastik.

- Vivah Chauki- The seat is specially prepared for the occasion of marriage. The wooden seat is provided by the groom's side and the background colour is yellow. A hundred petalled lotus is drawn over the surface with two parrots on the top left side- symbolic of an advance information of the arrival of the beloved.

- Dhuli Arghya Chauki: This Chauki is mainly made to welcome bridegroom. In the olden days bridegroom usually arrived during the evening or "Godhuli", at the time of sunset or Twilight. Since the groom represent "Narayan", so he is generally greeted with devotion. His dusty feet are carefully washed before the puja as he stands on a small stool or chaukil.

- Jyoti Patta In the hills of Kumaon, among the Brahmin and Sah families there is a practice of drawing a "Jyoonti" at a wedding or a sacred thread ceremony. In earlier times, "Jyoontis" were murals painted on the walls of rooms where religious ceremonies took place. "Jyoonti" is the local word used for the Jeev Matrikas - Maha Laxmi, Maha Saraswati and Maha Kali.

\section{c) Festivals}

- Durga Thapa The Durga Thapa is painted on paper by the women of Kumaon for Durga Pujas. This Thapa or painting is highly complex. This thapa depicts several local deities along with the many-armed Durga who rides the lion.

- Lakshmi Yantra- In the hills of Kumaon as in other parts of India, the goddess of wealth, Lakshmi, is worshipped during the festival of Diwali Kali Puja. The idol is placed on the spot where the Puja will take place. 
- Janmasthmi Patta- This is specially prepared for the worship of lord Krishna on the occasion of his Birthday.

The art is associated with a great degree of social, cultural as well as religious significance. Conventionally Aipan are not durable and erase over the time. It is essential to preserve this art in any of numerous creative art forms to save it for next generation.

\section{MATERIAL AND METHOD}

The aim of the study was to create a design pool, by the adaption of Aipan designs of Kumaun region for textile designing through appliqué work.

\section{a. Collection of prevalent Aipan designs}

Table 1. Total scores of evaluation for selected adapted design in each category

\begin{tabular}{|c|c|c|c|}
\hline \multirow[t]{2}{*}{ Categories } & Design & Total & Rank \\
\hline & No. & Score & \\
\hline \multirow[t]{2}{*}{ Centre } & 10 & 106 & I \\
\hline & 1 & 97 & II \\
\hline \multirow[t]{2}{*}{ Buti } & 2 & 213 & I \\
\hline & 10 & 211 & II \\
\hline \multirow[t]{2}{*}{ Border } & 2 & 213 & I \\
\hline & 5 & 211 & II \\
\hline
\end{tabular}

Traditional designs of Aipan of the Kumaun region were collected for the study from various secondary sources like books, cards, photographs and also through personal visit to houses of people living in Kumaun region.

\section{b. Adaptation of Aipan designs for appliqué work}

The selected motifs were used to develop designs for appliqué work without distorting the originality of the basic design. Thirty designs in different categories i.e., center design; border design and buti design were adapted to make them suitable for appliqué work. The designs were developed keeping in mind their suitability for articles like bags made from the discarded and waste

Table 2. Total scores obtained by selected arrangements

\begin{tabular}{l|l|l|l|}
\hline Categories & $\begin{array}{l}\text { Desig } \\
\text { n No. }\end{array}$ & $\begin{array}{l}\text { Tota } \\
\text { l } \\
\text { scor } \\
\text { e }\end{array}$ & $\begin{array}{l}\text { Ran } \\
\mathbf{k}\end{array}$ \\
\hline Mobile holder & 2 & 60 & I \\
\hline Pencil pouch & 3 & 52 & I \\
\hline Sling bag & 4 & 62 & I \\
\hline Back pack & 2 & 66 & I \\
\hline
\end{tabular}
fabric scraps.

The adapted designs were evaluated by panel of judges. The judges were asked to rank the designs in each category, from 1 to 10 on the basis of preference for suitability for appliqué work.

\section{c. Arrangement and evaluation of selected designs for different bags using Corel draw}

Different arrangements were prepared by using the selected designs for different bags viz., side bag, back bag, pencil pouch, mobile holder. For each article five arrangements were made using the combination of selected designs using Coral Draw software.

Corel Draw is a comprehensive vector based, also called object -oriented or draw images programme. The software is a robust graphics suite, providing many features for users to edit graphics. These features include contrast adjustment, color balancing, adding special effects like 
borders to images, and it is capable of working with multiple layers and multiple pages. All the selected motifs were digitized. The process of digitizing involves three basic steps: Intial one is the input of designs/ motifs, followed by processing of designs and the final step is the printing of designs [20].

The input of designs was done by copying it by coloured scanner. On opening the corel-draw software the designer has two options either to create a new file or to open an existing one. For development of arrangement, the entire motif/s were imported in to the new blank document or by dragging the picture from its location to the task bar icon of corel draw and dropped on to the new blank document. On opening of the new document, the name of file, height, width, size of paper, primary colour mode, and resolution of the designs have been specified. The processing of designs involved the editing of designs or creation of new designs using different tools. After entry of all the specification of working area, the CDR sheet with given specification is ready for design creation or editing. Editing of design includes modification of motifs, colour combinations by creating specific colour separations for printing. Creation involved the use of pen tool, free hand tool and outline pen tool to draw the outline of different bags as base, to give a proper view of the

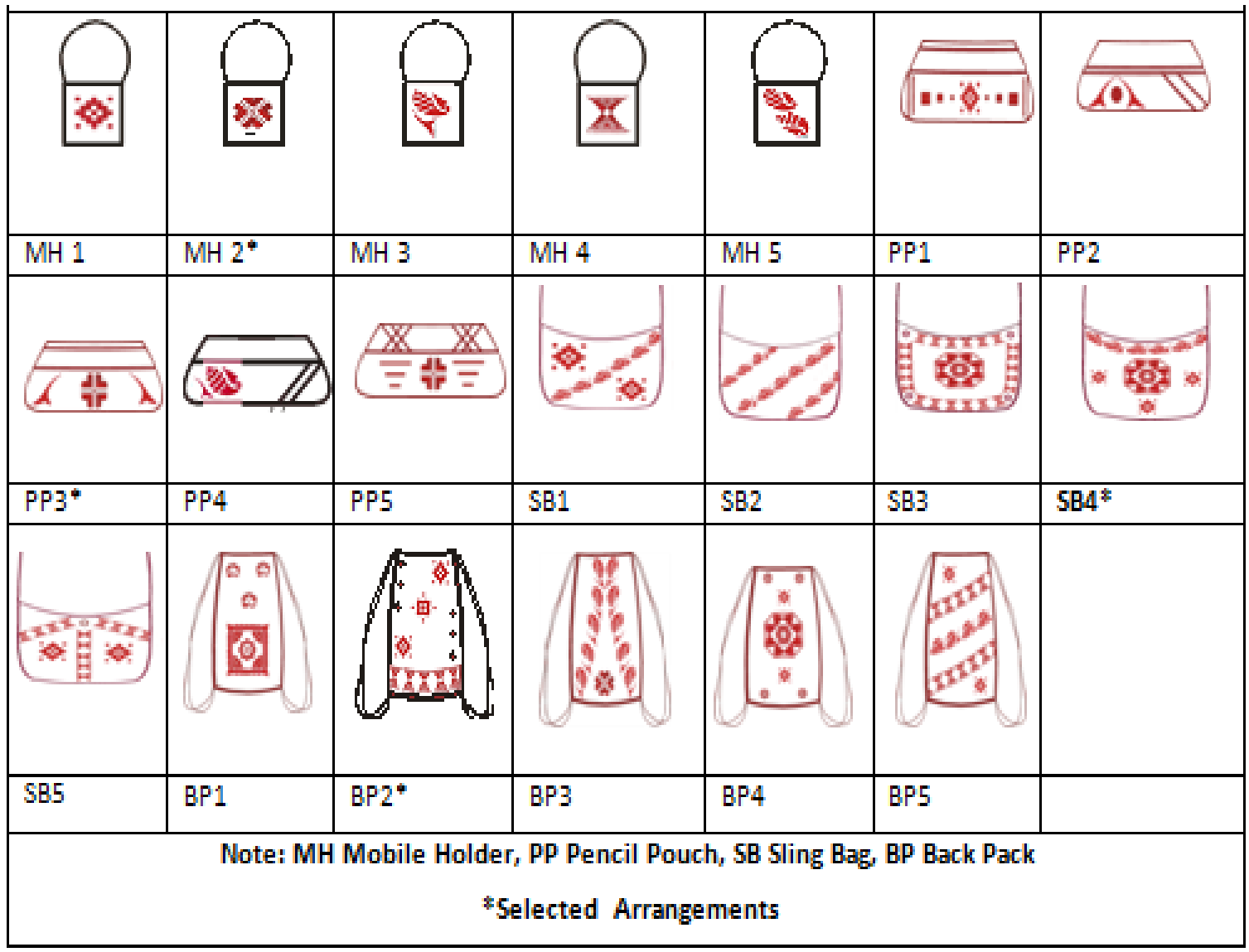

Figure 3: Designs Arrangement For Different Bags

design arrangement. After completing the outlines of bags, colours were filled with fill tool and 
colour eye dropper tool. Then the prepared motifs were arranged in the various bags. After completion of design arrangement, the software provides the save option as CDR or JPEG bitmaps file. The final printing of designs is to save the arrangement in printed form.

The developed arrangements were evaluated by a panel of 30 judges including staff members and students for assessing the acceptability of the developed designs on the basis of different attributes like suitability for appliqué work, arrangement of motif or designs and overall appearance. A five point ranking scale was used to evaluate the arrangements. The scores were 1, 2, 3, 4 and 5 corresponding to poor, fair, good, very good and excellent respectively. The arrangements scoring highest point in each category of bags were selected for final articles preparation.

\section{d. Material and Stitches used}

Plain red poplin was used for appliqué, as it frey less and can bear the temperature of iron while pressing. Fabric scraps and leftover fabric was used as base material. Different stitches like buttonhole, slip hemming, couching and chain stitch were used for fixing of appliqué work. Embroidery stitches serve a functional as well decorative purpose.

\section{e. Preparation of articles}

Finally one selected arrangement for each type of bag i.e., Side bags, back bags, pencil pouch and mobile holder were prepared. The prepared articles were evaluated by 30 consumers, to assess the acceptability. The prepared bags were assessed by the consumers in terms of suitability of embroidery stitch for appliqué work, neatness of embroidery, design arrangement, overall appearance and material used as base fabric and again 5 point ranking scale was used.

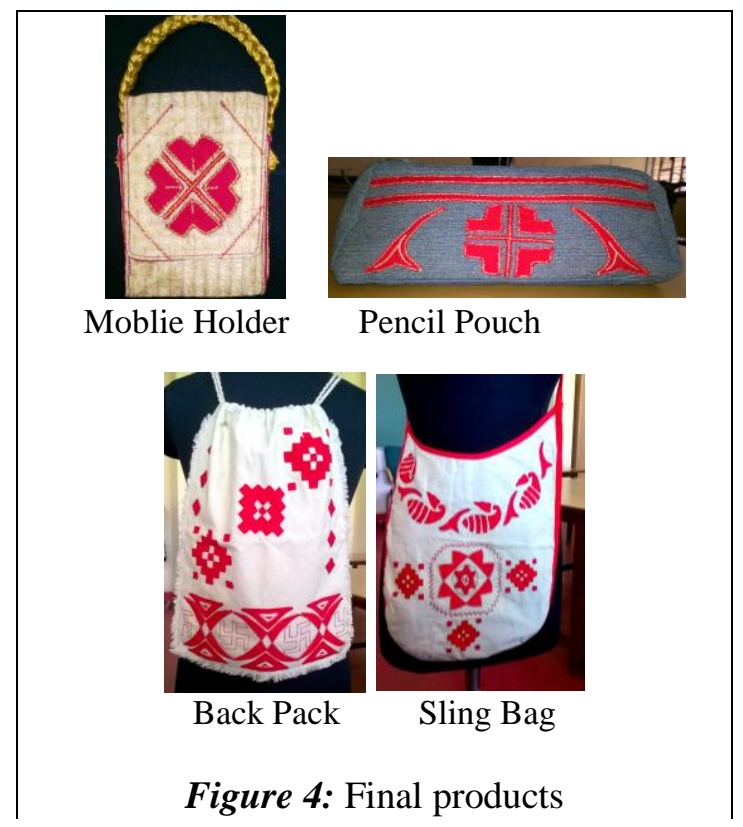

Assessment parameters for single product

Figure 5: Weighted Mean Scores Obtained

By Different Bags for Assessment

Parameters Evaluated By Consumers

Note: A: suitability of embroidery stitch for appliqué work B: neatness of embroidery C: Design arrangement D: Overall appearance E: Material used as base fabric 


\section{RESULT AND DISCUSSION}

\section{Collection of prevalent Aipan designs}

Total forty designs were chosen for adaptation, keeping in mind their utility for appliqué work. Out of which best ten motifs in categories i.e., centre, border and buti were selected by panel of judges for adaptation. The selected designs were shown in Fig 1. The traditional motifs of aipan were chosen for appliqué work as these are consists of shapes like triangle, circle, square, rectangular, dots and lines which are easy adapt for appliqué work.

\section{Adaptation and evaluation of Aipan designs for appliqué work}

Total thirty selected designs/ motifs in each category were adapted for appliqué work. The original motif or designs were adapted without distorting the originality of the basic design for appliqué work. The adapted motifs were shown in Fig 2. The total scores were calculated for each design; the two designs which scored highest marks were selected as the most preferred design in each category. The score of selected motifs were shown in Table 1.

\section{Development of Arrangement and their evaluation}

The selected motifs were used for different arrangements using Corel Draw Software. Thus total twenty arrangements for different bags were made using six selected motifs. The arrangements were shown in Fig 3. The final four arrangements were design no. 2 for mobile holder, design no. 3 for pencil pouch, design no. 4 for side bag, design no. 2 for back bag were selected. The score of

\begin{tabular}{|l|l|l|l|l|l|}
\hline \multicolumn{6}{|c|}{ TABLE 3. DISTRIBUTION OF RESPONDENTS ON } \\
COST OF DIFEERENT BAGS \\
\begin{tabular}{|l|l|l|l|l|} 
S. \\
No
\end{tabular} & $\begin{array}{l}\text { Param } \\
\text { eter }\end{array}$ & $\begin{array}{l}\text { Mobile } \\
\text { holder }\end{array}$ & $\begin{array}{l}\text { Pencil } \\
\text { purse }\end{array}$ & $\begin{array}{l}\text { Sling } \\
\text { bags }\end{array}$ & $\begin{array}{l}\text { Back } \\
\text { bag }\end{array}$ \\
\hline 1 & Low & $60 \%$ & $\begin{array}{l}33.33 \\
\%\end{array}$ & $\begin{array}{l}23.3 \\
\%\end{array}$ & $\begin{array}{l}86.66 \\
\%\end{array}$ \\
\hline 2 & $\begin{array}{l}\text { Appro } \\
\text { priate }\end{array}$ & $36.6 \%$ & $\begin{array}{l}63.33 \\
\%\end{array}$ & $\begin{array}{l}76.6 \\
\%\end{array}$ & $\begin{array}{l}13.33 \\
\%\end{array}$ \\
\hline 3 & High & $3.3 \%$ & $3.33 \%$ & - & - \\
\hline
\end{tabular}
selected arrangements were shown in Table 2

\section{Preparation and evaluation of appliqué articles}

Final four selected arrangements i.e., Arrangement no. 2 for mobile holder, arrangement no. 3 for pencil pouch, arrangement no. 4 for sling bag and arrangement no. 2 for back pack were prepared using appliqué embroidery. The final appreciated products are given in Fig 4. The prepared bags were appreciated by the consumers in terms of suitability of embroidery stitch for appliqué work, neatness of embroidery, design arrangement, overall appearance and material used as base fabric. It can be seen from Fig 5 that, back pack obtained highest weighted mean score (4.852) in all the assessment parameters followed by pencil purse and mobile holder with average weighted mean score of 4.244 and 4.028 respectively. The highest weighted mean scored parameter in all the bags was the suitability of embroidery stitch for appliqué work by the consumers.

It can be seen from Table 3 that there was variation in the views of consumers over the cost of the bags. 60 percent of total respondents reported that the cost of the mobile holder was low. However, 63.33 percent and 76.66 percent of total consumer found that the suggested cost was appropriate for pencil purse and sling bag respectively whereas, the suggested cost for back pack was found to be low according to 86.66 percent of the total respondents as they previously experienced that handmade and embroidered products were very expensive in different trade fair and exhibitions. 


\section{CONCLUSION}

Aipan of Uttarakhand is an example of Kumauni folk art having motif inspired from nature and mythology. Aipan designs show a blend of ethnic and natural yet stylized designs. Each and every Aipan design has a particular meaning attached to it and is drawn with a specific purpose in mind. The designs are intricate though simple to create and adapt. In fashion world, there is always a demand of something novel and artistic. The blend of Aipan design with appliqué is providing an imaginative and fresh collection to the people who want to adopt their tradition with minute modernization. Adapting and improving the designs refers to modify it such that it will be easier to produce, easier to use, or easier to fix, or easier to maintain so on. With the changing world of fashion the field of textile demands for unique, different and fresh designs which give us the opportunity to use the adapted traditional motifs.

All the designs and the product prepared by us are preferred by the immediate consumers. Thus, in the textile sector the adapted design can be used through the surface enrichment for product diversification and value addition. This will not only help in the preservation of Aipan but also broaden the design base for the textiles products. Women of Uttarakhand can also utilize their skills in experimenting with folk motifs and design to make them suitable for textile in innovative ways. This type of work also motivates people to come up with an ingenious work, which indirectly help in upgrading the art and craft of Uttarakhand and thus India's.

\section{ACKNOWLEDGEMENTS}

It is my profound privilege to express my deep sense of gratitude and indebtness to all the faculty memebers and friends, Department of Clothing and Textiles, college of Home ScienceG. B. P.U.A\& T, Pantnagar for her keen interest, continuous encouragement, intellectual guidance, constructive criticism and indispensable support.

\section{REFERENCES}

[1] Paul S. Grover E. and Sharma A. (2003). Application of natural dye berberis vulgaris on wool and its colourfastness. Man Made Textiles in India 46: 311-16.

[2] Sharma E.; Paul S. and Sheikh S. 2014. Fusion of Indian Folk Arts Madhubani and Warli for Designing of Apparels using CAD. (Electronic version). International Journal of Interdisciplinary Research. 1(8).

[3] Folk and tribal art. 2014. Retrieved on august 13 from https://www.storyltd.com/categories/fine-art/folk-and-tribal/

[4] Traditional crafts. 2013. Retrieved on May $5 \quad 2014$ from http://www.bharatheritage.in/traditional_crafts.htm

[5] Government of India. 2005. Folk and Tribal Art. Retrieved on 25 August 2015 from http://www.archive.india.gov.in/knowindia/culture_heritage.php.

[6] Joshi, S.C. 2013.Our art and statel: abode of gods and creativity. Retrieved on 25 Nov 2014 from http://uttarakhandarts.com/intro.htm

[7] Uttarakhand Handloom \& Handicraft Development Council (UHHDC).2013. handicraft Retrieved on 25 Aug, 2015 from https://www.uttarakhandcrafts.com/handicrafts.php 
[8] Markuna R. S. 2013. Aipan' designs luring domestic, global art lovers. Retrieved on 25 August, 2015 from http://www.dailypioneer.com

[9] Jerath, A. 1988. Aipans - folk paintings of Kumaun. The Indian textile magazine. 8(9):8084.

[10] Baral, B. 2013. Design Resources on Aipan- Uttarakhand ritual floor. Retrieved on 10 April, 2014 from www.dsource.in.

[11] Sen, N. 2012. Aipan : An Art of Uttarakhand. Retyrieved on 13 July 2015 from http://blog.lokrang.org/aipan-an-art-of-uttarakhand/

[12] Arts and crafts. 2012. Retrieved on November 11, 2014 from http://www.bharatonline.com/uttarakhand/arts-crafts/aipan

[13] Mathpal, Y. 1988. Kumaun painting. Uttaranchal, Garhwal Publications.129p.

[14] Shukla, S. 2010. Aipan- Kumauni Folk Art. Retreived on 30 Jan 2014 from www.himalayanheritage.blogspot.com

[15] Aipan. 2010. Retrieved on September, 232014 from http://www.culturalindia.net/indianart/rangoli/aipan.html

[16] Chattopadhay, K.1981. Handicrafts of India. New Delhi. Indin Council for Cutural Relation. PP25-37.

[17] Sah, V.N. 2006. Aipan: cultural motifs of kumaun. Nainital.Gyanodaya Prakshan 63p.

[18] Aipan and Other Art Forms. 2014. Retrieved on Aug, 182014 from http://www.euttaranchal.com/culture/kumaon/aipan.php

[19] Traditional Aipan. 2015. Retrieved on Aug, 182015 from http://www.99uttarakhand.in/traditional-aipan.php

[20] Corel draw. 2012. Retrieved on august $14 \quad 2015$ from http://www.computerhope.com/jargon/c/coreldraw.htm 